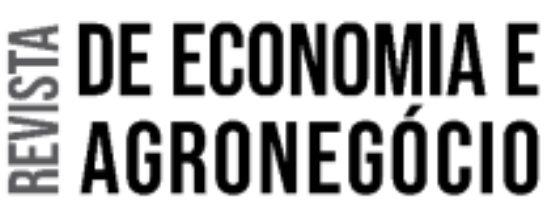

ISSN impresso: 1679-1614

ISSN online: $2526-5539$

Vol. 17 | N. 2 | 2019

Silvia Heleno ${ }^{1}$

Luckas Sabioni Lopes ${ }^{1^{*}}$

ORCID: 0000-0001-9059-3134

Chrystian Soares Mendes ${ }^{2}$

ORCID: $0000-0003-3406-4785$

1 Universidade Federal de Juiz de Fora, Governador Valadares, Minas Gerais, Brasil.

2 Universidade Federal de Ouro Preto, Mariana, Minas Gerais, Brasil.

* luckas.lopes@ufif.edu.br

\section{CICLOS DE NEGÓCIOS NOS SETORES INTENSIVOS EM TECNOLOGIA DA INDÚSTRIA DE TRANSFORMAÇÃO NO BRASIL}

\section{RESUMO}

O presente artigo buscou caracterizar e analisar os ciclos de negócios nos setores produtivos intensivos em tecnologia no Brasil, uma vez que estes assumem papel importante para o desempenho de longo prazo da economia. A base de dados variou entre os anos de 1991 e2014, com dados mensais, contemplando os ramos de: construção e montagem de aviões; equipamentos elétricos e de comunicação; produção de petróleo; produtos farmacêuticos; produtos plásticos; produtos químicos; e, veículos automotores. Após a construção de um indicador coincidente aos setores, foi possível perceber que o segmento em estudo exibe ciclos econômicos duas vezes mais acentuados que os da indústria em geral. As recessões têm duração de dez meses e perdas anualizadas de $10 \%$ em média, e as expansões perduram por 26 meses e geram ganhos de $8 \%$ a.a., o que indica assimetrias ao longo das fases dos ciclos. Outro resultado obtido pela decomposição da série coincidente mostra que a volatilidade nos setores se reduziu após a estabilização da economia, em 1994. Ainda assim, a alta sensibilidade a choques manifestada por esse ramo da atividade produtiva (em comparação com o total da indústria) sugere que ele seja um potencial alvo para a política industrial no país.

Palavras-chave: Ciclos de Negócios; Datação; Produção Industrial; Tecnologia.

\section{ABSTRACT}

This paper characterizes some business cycles facts in the Brazilian technology-intensive productive sectors since they assume a key role for long-term performance of the economy. Database varied from 1991 to 2014, with monthly data, including the sectors of construction and assembly of airplanes; electrical and communication equipment; oil production; pharmaceutical products; plastic products; chemical products; and, motor vehicles. After constructing a coincident index to the sectors, we found that the sector under study exhibits cyclic variations two times more pronounced than the ones in the general industry. Recessions durations were 10 months, with mean annualized losses of $10 \%$. Expansions averaged 26 months and generated gains of $8 \%$ p.a. This fact indicates asymmetries throughout the business cycles. Another result, obtained by the decomposition of the coincident indicator, showed that sectors' volatility declined after the stabilization of the economy in 1994. Nevertheless, the high sensitivity to shocks of this branch of productive activity (in comparison with the industry as a whole) suggests that it is a potential target for industrial policy in the country.

Keywords: Business Cycles; Dating; Industrial Production; Technology.

JEL Code: E32. 


\section{INTRODUÇÃO}

O conhecimento acerca dos principais indicadores do estado da economia é de suma importância para a atividade produtiva. $O$ processo de tomada de decisão dos diferentes agentes econômicos, privados ou públicos, ao definirem o destino de seus investimentos ou tratarem de problemas orçamentários, condução de políticas públicas, dentre outras questões, depende de uma noção prévia acerca da situação econômica no período: se de recessão ou de crescimento (DUARTE et al., 2004). Dessa forma, métodos de datação dos ciclos vêm tendo utilização crescente nas diversas esferas de produção.

Órgãos como o National Bureau of Economics Reserch (NBER), fundado em 1920 por Arthur Burns e Wesley Mitchell, que busca definir os picos e vales dispostos na atividade agregada nos Estados Unidos da América (EUA), e o The Conference Board (TCB), são responsáveis pelas informações sobre a atividade econômica daquele país. No Brasil, foi criado, em 2008, o Comitê de Datação de Ciclos Econômicos (CODACE), que concentra seus esforços em indicar uma cronologia mensal e trimestral que reflita os momentos de expansão e recessão do país a partir de 1980, com base na análise de diversos indicadores da atividade econômica.

No que diz respeito às aplicações desses conceitos no caso brasileiro, diversos trabalhos acadêmicos vêm sendo realizados de forma a preencher a defasagem de conhecimento formal existente, quando comparados com as informações disponíveis na literatura internacional no campo de pesquisa. Por exemplo, Chauvet (2002) analisou os ciclos de negócios no país e comparou diversos métodos de datação; Duarte et al. (2004) testaram, para os dados brasileiros, os métodos mais comuns de construção de indicadores coincidentes de nível agregado, observando uma maior adequação do método utilizado pelo TCB, resultado análogo ao alcançado por Hollauer et al. (2009); e, Lopes, Macedo e Toyoshima (2016) estudaram características dos ciclos de longo prazo do país, evidenciando flutuações com memória longa; entre vários outros estudos.

Entretanto, é possível observar, entre os trabalhos existentes na literatura nacional, uma necessidade de estudos adicionais para dados desagregados, setoriais, os quais são abordados pela presente pesquisa. Uma vez que os diferentes setores da economia podem responder de forma distinta às flutuações na atividade agregada, como bem definido por Burns e Mitchell (1946), espera-se que as informações aqui levantadas sejam relevantes para a área dos ciclos de negócios brasileiros.

O número de estudos comparativos entre a dinâmica dos setores e da atividade econômica agregada ${ }^{1}$ tem crescido recentemente. Long e Plosser (1987), analisando o caso norte-americano, lograram distinguir a parcela da co-movimentação setorial atribuída a choques agregados e a choques específicos, constatando que os primeiros explicam cerca de 50\% das movimentações totais. Contudo, Shea (2002), em suas estimações,

\footnotetext{
${ }^{1}$ No caso desta pesquisa, medida pela produção industrial geral.
} 
encontrou resultados que mostraram que os choques comuns explicaram de $50 \%$ a $95 \%$ da volatilidade da produção setorial, encontrando evidências de que parte ainda maior da volatilidade da atividade setorial nos EUA advém de co-movimentações ${ }^{2}$ interindustriais.

O presente estudo concentra-se nos setores produtivos intensivos em tecnologia da indústria de transformação brasileira. Assim, seguindo a taxonomia da Conferência das Nações Unidas sobre Comércio e Desenvolvimento (UNCTAD, 2002), as atividades selecionadas foram as referentes a: i) produção de petróleo; ii) materiais elétricos e de comunicação; iii) produtos químicos; iv) produtos plásticos; v) veículos automotores; vi) produtos farmacêuticos; e, vii) produção, montagem e consertos de aviões. A datação dos ciclos permitirá estabelecer um panorama da trajetória do desenvolvimento dos setores, associada às movimentações observadas na economia brasileira no período compreendido entre os anos de 1991 e 2014, com base em dados mensais.

Atualmente, a produção da indústria de transformação se encontra estagnada, sustentando um nível próximo ao observado em 2011, quando se dissiparam os efeitos das políticas anticíclicas adotadas durante a crise de 2008, as quais, mesmo tendo permitido uma rápida passagem da economia pela recessão, não surtiram efeitos sustentáveis de longo prazo. Frente a isso, o desempenho de setores relevantes para o crescimento de longo prazo da economia, por serem altamente intensivos em tecnologia, tem sido insatisfatório. Assim, verificar como os setores produtivos se comportam diante de flutuações econômicas é importante para a formulação de políticas, uma vez que as crises podem impactar a competitividade das firmas e, possivelmente, contribuir para a perda de participação no mercado nacional e internacional que se verifica nos dados ${ }^{3}$ (NASSIF, 2008). Ainda, levando em consideração a noção de que no longo prazo o crescimento econômico guarda forte relação com o progresso tecnológico (SOLOW, 1956), o estudo do comportamento dos setores de alta e média tecnologia e das suas respostas aos ciclos de negócios fornece uma boa base para entender questões como a sustentabilidade do processo de expansão da atividade econômica brasileira ao longo do tempo.

Especificamente, o presente estudo objetivou: i) caracterizar os ciclos de cada série de dados setorial, com a datação dos picos e vales e outras estatísticas relevantes, a fim de relacionar as oscilações observadas nesse setor com seu desenvolvimento ao longo dos anos; ii) construir um indicador coincidente para esse ramo da atividade industrial; e, iii) elaborar um modelo de previsão de movimentações cíclicas para o indicador coincidente.

$2 \mathrm{O}$ termo co-movimentação refere-se à correlação temporal de duas ou mais variáveis.

3 A título de ilustração, dados do Ministério da Indústria, Comércio Exterior e Serviços mostram que as exportações dos setores produtores de máquinas e aparelhos elétricos, indústrias químicas e correlatas e de plásticos e borracha têm caído constantemente desde o ano de 2011 (esses dados podem ser obtidos no site http://comexstat.mdic.gov.br/en/home). 
No presente trabalho, segue-se a tradição teórica e empírica originada em Slutzky (1937), a qual influenciou algumas teorias modernas dos ciclos econômicos, como a dos Ciclos Reais de Negócios (RBC). Na estrutura RBC padrão (ver Kydland e Prescott, 1982; e, Plosser, 1989, por exemplo), as variações dos agregados são geradas por choques tecnológicos aleatórios e são respostas de agentes otimizadores às perturbações recebidas. A teoria RBC obteve grande difusão no meio acadêmico, possivelmente em razão de sua construção baseada em microfundamentos e na evidência disponível internacionalmente de que as variáveis macroeconômicas, em sua maioria, teriam uma raiz unitária (Nelson e Plosser, 1982; King et al., 1991).

Entretanto, o debate acerca de uma estrutura teórica adequada à explicação das flutuações cíclicas das economias ainda está em aberto. Em particular, Caballero (2010) argumenta que, mesmo após muita calibração, os modelos RBC e os novo-Keynesianos só foram capazes de reproduzir oscilações leves na produção e obtiveram desempenho insatisfatório no que concerne às variações do nível geral de preços.

O restante do estudo está divido em outras três seções, além desta introdução. Na segunda seção, expõem-se o tratamento dos dados e as diversas metodologias utilizadas na pesquisa; na terceira, são apresentados os principais resultados e discussões; e, por fim, na quarta seção, apresentam-se as conclusões.

\section{TRATAMENTO DOS DADOS E METODOLOGIAS}

Os dados da produção industrial dos sete setores intensivos em tecnologia foram coletados junto ao Instituto Brasileiro de Geografia e Estatística, que disponibiliza levantamentos de dados mensais acerca da produção física de diversos setores de produção industrial ${ }^{4}$.

O período de tempo com maior disponibilidade de dados compreende o intervalo entre janeiro de 1991 e fevereiro de 2014, resultando em um total de 278 observações mensais para cada uma das sete séries, período de abrangência suficiente para que os ciclos pudessem ser extraídos sem estarem restritos aos de curta duração. Há uma amostra mais recente fornecida pelo IBGE, porém, sua utilização iria reduzir drasticamente a quantidade de ciclos econômicos disponíveis para análise ${ }^{5}$.

O indicador da produção industrial geral foi escolhido como a série de referência para as demais séries, a fim de se realizar análises comparativas entre os setores individuais e a atividade industrial agregada da economia. Preferiu-se esta ao produto interno bruto (PIB), pelo fato de a primeira estar disponível em dados mensais e seguir a mesma base metodológica dos

\footnotetext{
${ }^{4}$ Pesquisa industrial mensal, produção física. Disponibilizada pelo Instituto Brasileiro de Geografia e Estatística (IBGE/PIM-PF).

${ }^{5}$ Houve mudanças no método de levantamento por parte do IBGE a partir de 2014. A amostra mais recente é disponibilizada a partir de janeiro de 2002. No período, segundo informações do CODACE, o país passou por apenas três recessões (não obstante, a última delas foi uma das mais longas já datadas).
} 
dados setoriais. Ademais, ressalta-se que a produção industrial geral guarda forte correlação com as movimentações do produto agregado. Todas as séries foram logaritmizadas e tiveram o componente sazonal extraído pelo método Census X-12 aditivo. Apresentam-se, a seguir, os diversos métodos aplicados no estudo.

\section{Datação dos ciclos}

Bry e Boschan (1971) desenvolveram um algoritmo para a datação de ciclos (definição dos pontos de virada, ou turning points) em séries de periodicidade mensal, que visava a reproduzir as datas fornecidas pelo órgão NBER. Posteriormente, essa metodologia foi adaptada por Harding e Pagan (2002), que sintetizaram o processo de procura por picos e vales em duas regras básicas, além de possibilitarem sua aplicação a dados mensais e trimestrais - o método de Harding e Pagan (2002) é conhecido na literatura como BBQ.

O algoritmo BBQ parte de uma série de tempo convencional e tem como resultado uma série binária $\left\{S_{t}\right\}_{t=0}^{T}$, que mostra valor igual a 1 (um) quando a série se encontra em expansão, e 0 (zero) caso contrário ${ }^{6}$. Assim, assumindo $y_{\mathrm{t}}$ como o logaritmo da série de tempo dessazonalizada, os dois estágios da técnica referida são:

i) Um candidato a pico (ou vale) ocorrerá no tempo $t$, caso $y_{t}$ seja maior (ou menor) do que as $k$ observações anteriores e procedentes. Isto é, $y_{t}=$ máx $\left(y_{t-k}, \ldots, y_{t}, \ldots, y_{t+k}\right)$ representa um candidato a pico; e, um vale pode ser identificado quando $y_{t}=\operatorname{mín}\left(y_{t-k}, \ldots, y_{t}, \ldots, y_{t+k}\right)$;

ii) As fases de crescimento e de recessão, assim como a duração de um ciclo completo, devem satisfazer a determinação de uma duração mínima de $n_{1}$ e $n_{2}$ períodos, respectivamente.

Com base nos dados originais dos sete setores considerados, foram criadas séries temporais binárias com o algoritmo BBQ, as quais representam períodos de expansão e recessão. Os parâmetros utilizados no processo são padrões na literatura que trata sobre os ciclos de negócios (BURNS; MITCHELL, 1946): recomenda-se adotar $k=6$, demonstrando que um pico (ou vale) é identificado quando a série atinge um máximo (ou mínimo) local, se comparado aos valores observados nos seis meses anteriores e posteriores; $n_{1}=6$ e $n_{2}=15$, especificando que, respectivamente, um estado de expansão ou recessão deve durar ao menos seis meses e um ciclo completo (de pico a pico, ou de vale a vale) deve ter duração mínima de quinze meses. Essa determinação garante a alternância entre os pontos de transição e evita a ocorrência de vales e picos nos extremos da amostra.

Uma vez calculadas as séries de tempo binárias, é possível extrair algumas características de interesse das flutuações econômicas. Por exemplo, realizando uma estimação do tipo $S_{t}=\alpha+\beta S_{t-1}$, em que $S_{t}=1$ nas 
expansões, a duração média dessa fase é obtida resolvendo $\hat{D}=1 /(1-\hat{\alpha}-\hat{\beta})$ . A amplitude estimada, $\hat{A}$, ou seja, a variação percentual média de uma série em sua fase de expansão é dada pelo coeficiente angular da regressão entre $\Delta y_{t} \mathrm{e}^{S_{t}}$. Os ganhos (ou perdas) acumulados da expansão (ou recessão), $C$, dependem da duração da fase e de sua amplitude de variação. Na maioria dos casos práticos, a aproximação triangular ${ }^{7}$ estima bem essas informações, bastando para tal aplicar a fórmula $\hat{C}_{T}=1 / 2 \times(\hat{D} \times \hat{A})$ (HARDING; PAGAN, 2002). Essas medidas são utilizadas para caracterizar e comparar as séries de tempo consideradas no estudo.

\section{Indicadores de correlação entre as fases}

A sincronização entre ciclos de diferentes séries pode ser visualizada, graficamente, como uma aglomeração dos pontos de transição em intervalos de tempo que se repetem com relativa frequência. Harding e Pagan (2006) apresentam vasta discussão acerca das medidas de sincronização entre séries e suas fases. De acordo com os autores, consideram-se duas variáveis aleatórias binárias, $S_{x t}$ e $S_{y t}$, indicando, respectivamente, se as séries $x_{t}$ e $y_{t}$ estão em uma fase de crescimento (nesse caso, as variáveis assumem valor 1 ). Define-se, então, a estatística $\rho_{S}$, que mede o grau de associação linear entre $S_{x t}$ e $S_{y t}$, em que $\left|\rho_{s}\right| \leq 1$.

Como os estados obtidos em momento anterior, $S_{x t}$ e $S_{y t}$, provavelmente são serialmente correlacionados, a estimação de $\rho_{s}$ deve ser feita com um estimador robusto das variâncias $\sigma_{S x}^{2}$ e $\sigma_{S y}^{2}$. Assim, o procedimento prático para a estimação do grau de sincronização entre as séries passa pelo método dos mínimos quadrados ponderados, conforme a seguinte equação:

$$
\hat{\sigma}_{S x}^{-1} \hat{\sigma}_{S y}^{-1} S_{y t}=\alpha+\rho_{S} \hat{\sigma}_{S x}^{-1} \hat{\sigma}_{S y}^{-1} S_{x t}+u_{t}
$$

em que se assume $u_{t}$ como um processo estocástico de ruído branco; sendo $\alpha$ o intercepto. A estimação de $\rho_{s}$ mediante a expressão (1) é vantajosa, pois se podem escolher estimadores de variância e covariância eficientes na presença de heterocedasticidade e autocorrelação (como o de White ou de Newey-West). Além disso, a utilização de métodos de regressão proporciona um teste direto da hipótese $\rho_{s}=0$, conforme a estatística $t$ Student.

Essas medidas de correlação informarão em que grau um dado setor produtivo responde a choques, em outros ramos da atividade econômica, e qual a associação entre as fases dos setores e da atividade econômica agregada.

\footnotetext{
${ }^{7}$ Esse método recebe o nome de aproximação triangular, pois, ao considerar a duração no eixo horizontal (base) e a amplitude no eixo vertical (altura), o ganho total é bem estimado pela área de um triângulo.
} 


\section{A construção do indicador composto do setor tecnológico}

A construção de um indicador composto (síntese) para as flutuações cíclicas nos setores intensivos em tecnologia depende de um razoável grau de movimentação conjunta entre as séries individuais. Nesse sentido, além de verificar a correlação par a par entre as séries, com o método descrito anteriormente, analisam-se as possíveis concentrações das fases dos setores como um todo, com intermédio de indicadores de difusão. Chang e Hwang (2015) expõem que o índice de difusão $\left(D_{t}\right)$, descrito na equação (2), mede a proporção das indústrias que estão na mesma fase, em determinado momento, sendo que, matematicamente:

$$
D_{t}=1 / N \sum_{i=1}^{N} S_{i t}
$$

em que, $S_{i t}$ é a variável binária que relata se o setor encontra-se em expansão $\left(S_{i t}=1\right)$ ou recessão $\left(S_{i t}=0\right)$; e, $N=7$ representa o número de setores industriais analisados. Uma vez verificado o valor da medida $D_{t}$, tem-se indicações da viabilidade da criação de um indicador comum para as séries do estudo.

Para a estimação da série temporal comum aos setores de média e alta tecnologia, utiliza-se o método baseado no empregado pelo TCB, que calcula indicadores coincidentes para diversos países. Esse método é aplicado por Duarte et al. (2004) para a obtenção de um indicador coincidente do nível da atividade econômica agregada brasileira. Sugere-se a consulta a esses autores para uma descrição pormenorizada do procedimento. Porém, é válido destacar que ese método pondera igualmente as séries, após elas terem sido padronizadas em função de suas volatilidades.

Além disso, outras possibilidades foram testadas. Com pesos proporcionais ao valor adicionado médio da produção nos setores (entre 2007/2016), obteve-se uma série coincidente muito influenciada por poucos ramos da atividade. Especificamente, mais de $75 \%$ do índice foi composto pela produção de petróleo, automóveis e químicos. Outra possibilidade foi calcular ponderações proporcionais aos coeficientes do primeiro componente principal extraído da matriz de correlação dos dados, que explicou $70 \%$ da variabilidade total. Os pesos obtidos foram similares para todas as variáveis, exceto para a produção do setor elétrico. Contudo, esses indicadores não apresentaram bom desempenho, com datações de picos e vales que não representavam adequadamente a realidade dos setores individuais e desconsideravam datas importantes para a produção industrial, como a época da última crise financeira mundial.

Como se vê, a seguir, os setores de alta e média tecnologia (tomados separadamente) guardam forte coincidência com a atividade industrial geral, o que determinou a decisão pela não adoção dessas duas possibilidades. 


\section{Um modelo econométrico para o indicador coincidente}

Análises baseadas na caracterização de picos e vales da produção servem como guia para a formulação de políticas, uma vez que elas indicam as fases em que a economia se encontra ao longo de sua dinâmica. Elas são baseadas na visão clássica do ciclo econômico (business cycles), originada por estudos similares aos de Burns e Mitchell (1946) e amplamente divulgada por órgãos como o NBER, os quais defendem uma indissociabilidade entre tendência e ciclo, uma vez que choques macroeconômicos poderiam afetar ambos os componentes, simultaneamente.

Outra vertente de análise dos ciclos econômicos se fundamenta na tentativa de caracterização, mediante algum método estatístico ou processo de filtragem, de uma tendência temporal suave e de uma série cíclica da produção (growth cycles). Esta última abordagem tem o benefício de gerar uma variável cíclica que não somente representa os altos e baixos da atividade, mas também permite o uso de métodos que façam previsões a respeito das magnitudes de variação dos agregados.

Nota-se que as duas formas de análise podem produzir fatos estilizados (estatísticas dos ciclos econômicos) diferentes. A respeito disso, recomendase a leitura de Zarnowitz e Ozyildirim (2006). Com o intuito de minimizar esse problema, utilizou-se o método de decomposição tendência-ciclo de componentes não observáveis, bastante disseminado na literatura econômica ${ }^{8}$ (CLARK, 1987; HARVEY; JAEGER, 1993; MORLEY; NELSON; ZIVOT, 2003; e, PERRON; WADA, 2009).

Harvey (1993) descreve o modelo de componentes não observáveis utilizado nesta pesquisa da seguinte forma:

$$
I C_{t}=\theta_{t}+\varphi_{t}+\varepsilon_{t}, \quad t=1, \ldots T,
$$

em que $I C_{t}$ representa a série coincidente; $\theta_{t}$ é a tendência temporal, do tipo local linear; $\varphi_{t}$ é o componente cíclico, estimado como um processo $\operatorname{AR}(1)^{9}$; e $\varepsilon_{t}$ denota o componente puramente irregular com variância $\sigma_{\varepsilon}^{2}$. A estimação dos parâmetros do modelo é obtida maximizando a função de verossimilhança da especificação em um formato de filtro de Kalman. As séries de tendência e ciclo são geradas por um algoritmo de suavização. Os cálculos foram implementados no software econométrico Oxmetrics, pacote STAMP.

\footnotetext{
8 O método de componentes não observáveis estima um componente tendência e outro cíclico, como na escola dos ciclos de crescimento, mas o faz com um procedimento de etapa única, modelando ambos os componentes conjuntamente, relacionando-se com as ideias de indissociabilidade dos ciclos de negócios.

9 Especificações mais gerais para o componente cíclico também foram avaliadas, mas os resultados obtidos a partir desse modelo mais simples foram satisfatórios.
} 


\section{RESULTADOS E DISCUSSÕES}

\section{Uma análise prévia da produção agregada}

Nesta seção, caracterizam-se possíveis associações entre as oscilações econômicas dos setores de alta tecnologia e as observadas na economia brasileira como um todo. Por se tratar da série de referência, com a qual são comparados os setores em separado, estão dispostas nas Tabelas 1 e 2 as datas dos picos e vales extraídas para o indicador da atividade industrial. Ademais, essas tabelas descrevem a duração, as taxas de crescimento acumuladas (de vale a pico) e a taxa média de crescimento nas fases (Tabela 1); bem como a duração, as taxas de decrescimento acumulado (de pico a vale) e a taxa de perda média nas fases recessivas (Tabela 2).

Foram verificadas, para o indicador brasileiro de produção industrial geral, expansões que duram, em média, 26 meses (pouco mais de dois anos), com taxa de crescimento médio de $1,99 \%$ ao ano.

Tabela 1. Expansão na atividade industrial geral no período de 1991-2014

\begin{tabular}{ccccc}
\hline \multicolumn{5}{c}{ Expansões } \\
\hline Início & Fim & $\begin{array}{c}\text { Duração (em } \\
\text { meses) }\end{array}$ & $\begin{array}{c}\text { Cresc. (\%) Acumulado } \\
\text { de Vale a Pico }\end{array}$ & $\begin{array}{c}\text { Média } \\
\text { (\%) Anualizada }\end{array}$ \\
\hline Nov./93 & Nov./94 & 13 & $3,94 \%$ & $3,64 \%$ \\
Ago./95 & Set./97 & 26 & $3,07 \%$ & $1,42 \%$ \\
Mar./99 & Nov./00 & 21 & $2,77 \%$ & $1,58 \%$ \\
Jan./02 & Set./02 & 9 & $1,57 \%$ & $2,09 \%$ \\
Jul./03 & Ago./08 & 62 & $6,25 \%$ & $1,21 \%$ \\
\hline Média & & 26,2 & $3,52 \%$ & $1,99 \%$ \\
\hline
\end{tabular}

Fonte: Elaboração própria.

Entre novembro de 1993 e novembro de 1994, a produção industrial cresceu $3,94 \%$, refletindo as medidas de estabilização do início da década, anteriores ao Plano Real. Em agosto de 1995, a indústria experimenta nova fase de expansão e se mantém crescendo até setembro de 1997, em 3,07\%. Tal movimento pode ser associado ao êxito do Plano Real na estabilização da economia, uma vez que a estabilização inflacionária tende a beneficiar a atividade produtiva real (FRIEDMAN, 1977; FISCHER, 1993; e, EVANS; WACHTEL, 1993). Essa expansão foi a segunda mais importante da amostra, a despeito das elevadas taxas de juros básicas do período (a taxa Selic média entre 1995 e 1997 foi de 40\% a.a.).

A mais longa fase de expansão observada na produção industrial agregada se dá entre julho de 2003 e agosto de 2008, antes do estopim da crise econômica e financeira internacional. Nesse período, a condução da política manteve-se comprometida em assegurar o controle fiscal e monetário, principalmente em meio a um cenário de forte incerteza política. A produção industrial seguiu a recuperação da economia nessa fase, com um crescimento acumulado, entre o referido pico prévio até o próximo vale, de 
cerca de 6,25\%, resultado favorecido por um ambiente de taxa de inflação decrescente, melhoria nas contas externas, superávit primário e redução das taxas de juros (WERNECK, 2014).

As recessões da produção industrial geral têm duração média de 16,5 meses, ou seja, aproximadamente 1,5 anos, e uma taxa de decrescimento de 1,4\% ao ano. As quedas acumuladas de pico a vale são estimadas, em média, em 1,24\%. Em geral, as recessões registradas são mais curtas que as expansões. Porém, até 2003, as variações acumuladas nas fases de queda foram maiores do que as observadas nos períodos de crescimento. Tal fato indica assimetrias nos ciclos de negócios no país. Pode-se afirmar que, no Brasil, as fases de crescimento tendem a ser mais longas e suaves e as recessões mais curtas e abruptas.

A primeira recessão datada na amostra, observada entre outubro de 1991 e outubro de 1993, que se desdobrou por cerca de dois anos, reflete os efeitos do descontrole da economia durante boa parte da década de 1980. No início da década de 1990, os esforços foram direcionados para a estabilização macroeconômica e o controle da inflação. Além disso, as medidas impostas, no início da década, tais quais os congelamentos de preços, reajustes das correções monetárias dos títulos públicos, aumento das taxas de juros reais, entre outras, culminaram em um aperto de liquidez que, combinado com o cenário incerto da economia, afetou de maneira significativa a produção industrial (ABREU; WERNECK, 2014).

Tabela 2. Recessões na atividade industrial geral no período de 1991-2014

\begin{tabular}{ccccc}
\hline \multicolumn{5}{c}{ Recessões } \\
\hline Início & Fim & $\begin{array}{c}\text { Duração (em } \\
\text { meses) }\end{array}$ & $\begin{array}{c}\text { Perda (\%) Acumulada } \\
\text { de Pico a Vale }\end{array}$ & $\begin{array}{c}\text { Média } \\
\text { (\%) Anualizada }\end{array}$ \\
\hline Out./91 & Out./93 & 25 & $-0,55 \%$ & $-0,26 \%$ \\
Dez./94 & Jul./95 & 8 & $-2,86 \%$ & $-4,29 \%$ \\
Out./97 & Fev./99 & 17 & $-1,88 \%$ & $-1,33 \%$ \\
Dez./00 & Dez./01 & 13 & $-0,51 \%$ & $-0,47 \%$ \\
Out./02 & Jun./03 & 9 & $-1,51 \%$ & $-2,01 \%$ \\
Set./08 & Out./10 & 26 & $-0,12 \%$ & $-0,06 \%$ \\
\hline Média & \multicolumn{5}{c}{$-1,24 \%$} & $-1,40 \%$ \\
\hline
\end{tabular}

Fonte: Elaboração própria.

Logo após um curto período em expansão, a produção industrial passa por uma crise de elevada magnitude entre dezembro de 1994 e julho de 1995, consequência das políticas macroeconômicas vigentes no início da implementação do Plano Real, entre elas o aumento das taxas de juros reais e a manutenção de uma taxa de câmbio valorizada como uma forma de âncora nominal. A perda acumulada do período ficou em torno de 2,9\%.

Entretanto, a crise de maior duração aconteceu entre setembro de 2008 e outubro de 2010, somando 26 meses de queda, o que mostra seu efeito duradouro sobre a produção industrial, com a depreciação do real, a redução da oferta de crédito internacional e a redução dos níveis de 
produção e exportação (FREITAS, 2009). Contudo, o percentual da perda associada a esse vale foi baixo, possivelmente um retrato das tentativas do governo de recompor o nível do produto durante a crise mundial, com fortes incentivos à demanda agregada via redução das taxas de juros e aumento nos gastos públicos (PASTORE; GAZZANO; PINOTTI, 2013).

Foi identificado um total de sete períodos de recessão para a produção industrial no Brasil, representados na Figura 1, a seguir, pelas áreas acinzentadas. A linha pontilhada ilustra o último ponto de transição (pico) extraído dos dados.

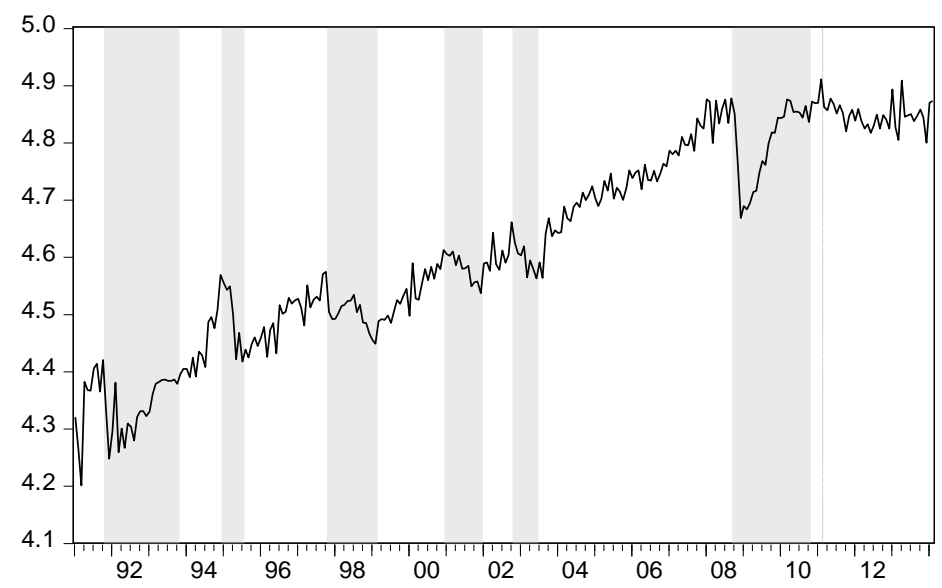

Figura 1. Recessões da produção industrial geral no Brasil, 1991-2014

Fonte: Elaboração própria.

Nota: Recessões ilustradas pelas áreas acinzentadas; os dados foram logaritmizados.

A partir da década de 1990, deu-se início, no Brasil, a uma série de reformas e medidas que visavam a estimular a produção industrial (ABREU; WERNECK, 2014). Em nível agregado, a abertura comercial, a queda da participação do Estado na economia, as privatizações e os novos regimes de importação procuravam ampliar a produtividade das indústrias brasileiras, a inserção no mercado internacional e a qualidade dos processos produtivos. Contudo, como se vê na Tabela 1, as taxas de crescimento acumuladas do início da amostra foram modestas. Isso pode ser reflexo do processo de ajustamento da produção à maior exposição ao mercado externo, em conjunção com uma política monetária de altas taxas de juros reais, como as vigentes entre 1994 e 1997. Em termos desagregados, as políticas industriais têm sido direcionadas ao fornecimento de incentivos fiscais diretos e à proteção de alguns setores. Tais ações são intensificadas após o ano de 2003, e, em conjunção com o mercado externo favorável, podem explicar o longo período de expansão verificado entre 2003 e 2008.

\section{Ciclos de negócios nos setores de média e alta tecnologia}

Analisam-se agora os dados desagregados da produção no país. A Tabela 3 sumariza as durações médias das expansões estimadas para as sete séries, 
obtidas mediante um processo de datação similar ao implementado anteriormente. A duração média das fases de crescimento, nos ramos industriais considerados, é de aproximadamente 21 meses, isto é, quase dois anos. Destaca-se, ainda, o setor de construção e montagem de aviões, cujas expansões se estenderam, em média, por três anos e meio, maior período entre as séries da amostra. Sua maior expansão durou 67 meses, datada entre janeiro de 2002 e julho de 2007. Por outro lado, o setor de equipamentos elétricos e de comunicação se sobressai por apresentar fases de crescimento com menor duração, com média de um ano aproximadamente.

Tabela 3. Durações médias das expansões, em meses, por setor, no período de 1991-2014

\begin{tabular}{lccc}
\hline \multicolumn{1}{c}{ Setor } & Média & Maior & Menor \\
\hline Construção e montagem de aviões & 41 & 67 & 13 \\
Equipamentos elétricos e de comunicação & 13 & 25 & 4 \\
Produção de petróleo & 19 & 46 & 9 \\
Produtos farmacêuticos & 15 & 54 & 8 \\
Produtos plásticos & 20 & 32 & 7 \\
Produtos químicos & 16 & 34 & 5 \\
Veículos automotores & 22 & 39 & 5 \\
\hline Indústria Geral & 26 & 62 & 9 \\
\hline \hline
\end{tabular}

Fonte: Elaboração própria.

Com as datas de picos e vales estimadas para cada setor, é possível calcular a variação percentual média das expansões da produção, entre outras estatísticas. A Tabela 4 traz essas informações, permitindo uma análise resumida de características associadas às expansões nos setores, bem como uma comparação entre estas e os valores observados para a série da produção industrial geral. Os setores apresentaram, em conjunto, um crescimento médio de 5,22\% a.a., bem superior à média da indústria. Assim, é possível verificar que as altas dos setores tecnológicos foram mais vigorosas do que as datadas para a produção da indústria agregada.

A produção de equipamentos elétricos e de comunicação apresentou a maior média de crescimento anual ao longo dos 23 anos analisados, seguida do setor de construção e montagem de aviões. O valor calculado foi de 9,76\% a.a., um percentual bastante elevado, tanto em relação aos demais ramos, como em relação à expansão observada na indústria (a maior taxa foi observada entre janeiro de 2009 e setembro do mesmo ano, período em que o setor cresceu em torno de $15 \%$ ). O setor de construção e montagem de aviões apresentou variação percentual média de $9,6 \%$ a.a. nos períodos de crescimento, especialmente entre dezembro de 2007 e dezembro de 2008, quando o setor cresceu cerca de 19\% a.a. Os ramos de produção de petróleo e de produtos plásticos apresentaram as menores médias de crescimento anual, com valores associados de 1,45\% a.a. e 3,09\% a.a., respectivamente. 
Tabela 4. Análise resumida das estatísticas referentes às expansões por setor, no período de 1991-2014

\begin{tabular}{lccc}
\hline \multicolumn{1}{c}{ Setor } & Média & Maior & Menor \\
\hline \hline Construção e montagem de aviões & $9,60 \%$ & $18,99 \%$ & $3,15 \%$ \\
Equipamentos elétricos e de comunicação & $9,76 \%$ & $14,84 \%$ & $5,85 \%$ \\
Produção de petróleo & $1,45 \%$ & $2,77 \%$ & $0,45 \%$ \\
Produtos farmacêuticos & $4,77 \%$ & $10,11 \%$ & $1,29 \%$ \\
Produtos plásticos & $3,09 \%$ & $11,15 \%$ & $0,79 \%$ \\
Produtos químicos & $3,42 \%$ & $5,84 \%$ & $0,70 \%$ \\
Veículos automotores & $4,47 \%$ & $6,07 \%$ & $1,31 \%$ \\
\hline Média dos setores & $5,22 \%$ & $9,97 \%$ & $1,93 \%$ \\
\hline Indústria Geral & $1,99 \%$ & $3,64 \%$ & $1,21 \%$ \\
\hline \hline
\end{tabular}

Fonte: Elaboração própria.

A Tabela 5 apresenta a duração média das recessões observadas nos setores. Pode-se verificar que as durações médias dos períodos de queda da atividade nos setores são menos discrepantes que as médias das expansões (vide Tabela 3), sendo estimadas entre 11 e 19 meses. Salvo a recessão no ramo de produção de equipamentos elétricos e de comunicação, todas as fases recessivas dos setores mantiveram-se com duração média abaixo da encontrada para a indústria geral.

Tabela 5. Durações médias das recessões, por setor, no período de 19912014

\begin{tabular}{lccc}
\hline \multicolumn{1}{c}{ Setor } & Média & Maior & Menor \\
\hline Construção e montagem de aviões & 12 & 28 & 4 \\
Equipamentos elétricos e de comunicação & 19 & 38 & 9 \\
Produção de petróleo & 14 & 27 & 4 \\
Produtos farmacêuticos & 11 & 16 & 6 \\
Produtos plásticos & 12.9 & 17 & 8 \\
Produtos químicos & 14 & 25 & 8 \\
Veículos automotores & 12 & 19 & 4 \\
\hline Indústria Geral & 16.5 & 26 & 8 \\
\hline \hline
\end{tabular}

Fonte: Elaboração própria.

Com duração média de 12 meses, as oito recessões encontradas para o setor de veículos automotores refletiram um decrescimento médio da produção de 7,6\% a.a., a segunda maior perda acumulada durante os anos considerados, atrás apenas da variação observada no ramo de construção e montagem de aviões, de $-13,13 \%$ a.a. A Tabela 6 traz essas informações para todos os ramos produtivos em estudo.

O ramo da produção e refino de petróleo se destaca pela relativa estabilidade, apresentando flutuações com durações médias e variações acumuladas reduzidas. Valores próximos são encontrados nos casos de produtos químicos, produtos farmacêuticos e produtos plásticos. 
Em suma, observa-se que o comportamento desagregado dos setores intensivos em tecnologia é, em boa parte, consonante em termos de duração média dos ciclos de crescimento e recessão. Em comparação com a indústria geral, percebe-se que suas flutuações têm durações mais curtas, porém, são mais acentuadas.

Tabela 6. Análise resumida das estatísticas referentes às recessões por setor, no período de 1991-2014

\begin{tabular}{lccc}
\hline \multicolumn{1}{c}{ Setor } & Média & Maior & Menor \\
\hline \hline Construção e montagem de aviões & $-13,13 \%$ & $-4,02 \%$ & $-23,33 \%$ \\
Equipamentos elétricos e de comunicação & $-6,39 \%$ & $-0,16 \%$ & $-15,16 \%$ \\
Produção de petróleo & $-2,12 \%$ & $-0,35 \%$ & $-7,93 \%$ \\
Produtos farmacêuticos & $-3,72 \%$ & $-1,87 \%$ & $-8,15 \%$ \\
Produtos plásticos & $-3,29 \%$ & $-1,10 \%$ & $-7,62 \%$ \\
Produtos químicos & $-2,39 \%$ & $-0,55 \%$ & $-5,07 \%$ \\
Veículos automotores & $-7,60 \%$ & $-2,14 \%$ & $-24,80 \%$ \\
\hline Média dos setores & $-5,52 \%$ & $-1,46 \%$ & $-13,15 \%$ \\
\hline Indústria Geral & $-1,40 \%$ & $-0,06 \%$ & $-4,29 \%$ \\
\hline \hline
\end{tabular}

Fonte: Elaboração própria.

\section{Índice de difusão}

O índice de difusão permite a visualização da parcela do conjunto dos setores produtivos que se encontra em uma mesma fase do ciclo (crescimento ou recessão) em determinado ponto do intervalo analisado, funcionando como uma medida da co-movimentação entre as séries de tempo. A Figura 2 ilustra o comportamento de tal indicador durante as recessões.

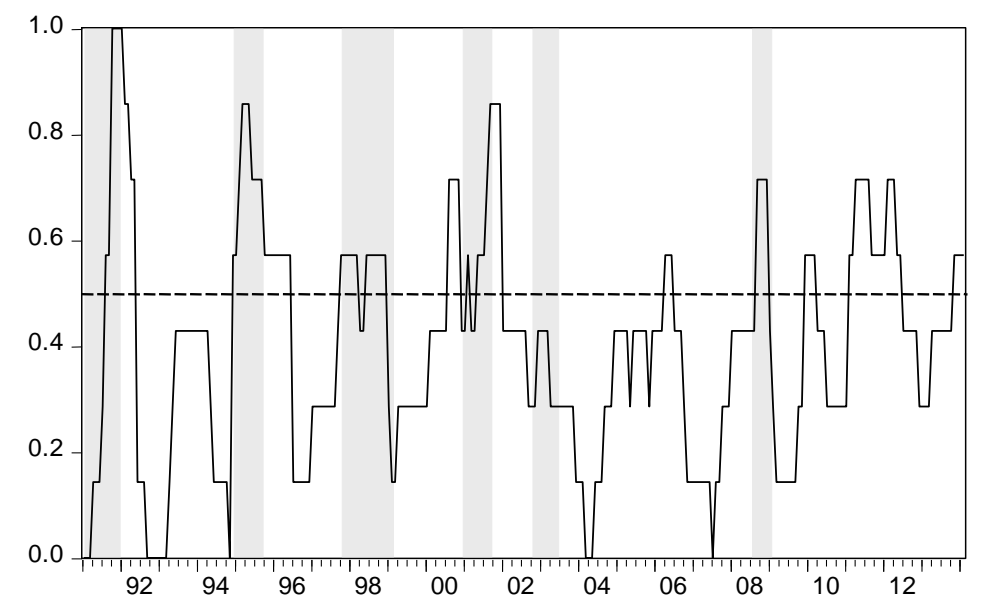

Figura 2. Índice de difusão setorial nas recessões no período de 1991-2014

Fonte: Resultados da pesquisa.

Nota: Áreas cinzas representam recessões da economia geral. A linha tracejada representa $50 \%$. 
As áreas cinzas demarcam as quedas da atividade produtiva, conforme datação do CODACE. É possível observar que o índice flutua em proximidade com a atividade agregada, isto é, nas recessões da economia, geralmente, mais de $50 \%$ dos setores considerados de média e alta tecnologia também se encontravam nessa fase. As principais exceções ocorrem na recessão de 2002/03, que não afetou significativamente a maioria dos setores em análise, e após a crise financeira de 2008, quando a atividade agregada se normalizou mais rapidamente do que a produção industrial setorial. Conforme é possível notar, o índice de difusão aumenta nas seis recessões observadas pelo comitê nacional para o período, destacando-se as recessões de 1989 a 1992 e de 1995, 2001 e 2008, quando a produção de quase todos os setores também se reduziu.

A análise do índice de difusão fornece uma boa base para inferir que os sete setores analisados na pesquisa apresentaram concordância entre si em relação às fases recessivas e à atividade como um todo. Tal demonstração indica ser plausível a criação do indicador coincidente para os ramos da indústria de transformação intensivos em tecnologia. Esse fato é corroborado pelas informações das tabelas presentes no Anexo (Tabela 1A e 2A), que mostram as correlações entre as fases de crescimento e recessão em cada par de setores.

Nos momentos de recessão, destaca-se o fato de que, dentre as combinações observadas, extraíram-se correlações superiores a 0,5 em cerca de 70\% dos casos, níveis satisfatórios para os fins deste estudo ${ }^{10}$. De forma análoga, as correlações entre as fases de crescimento foram superiores a esse valor em quase $80 \%$ das combinações de pares de setores. A análise das matrizes de correlação para as duas fases ratifica o resultado encontrado pelo índice de difusão e fornece indícios de que o indicador coincidente contenha as sete séries escolhidas a priori neste estudo.

Assim, a Figura 3 representa a série que resume as movimentações dos setores como um todo, utilizando o método descrito anteriormente. A série do indicador coincidente foi submetida aos mesmos processos realizados sobre as séries anteriores, isto é, a datação dos pontos de transição entre as fases recessivas e expansivas, bem como a estimativa da duração e amplitude médias de cada fase.

O indicador apresenta a tendência de crescimento da atividade produtiva do setor no período entre 1991 e 2014, com as áreas acinzentadas delimitando suas fases recessivas. O resultado encontrado pelo indicador coincidente apresenta elevado grau de conformidade com o obtido para a indústria geral, o que era esperado, uma vez analisado o indicador de difusão e sua alta correlação com a atividade agregada.

${ }^{10}$ É comum utilizar a regra prática de que correlações acima de 0,5 em módulo indicam associação moderada a forte. 


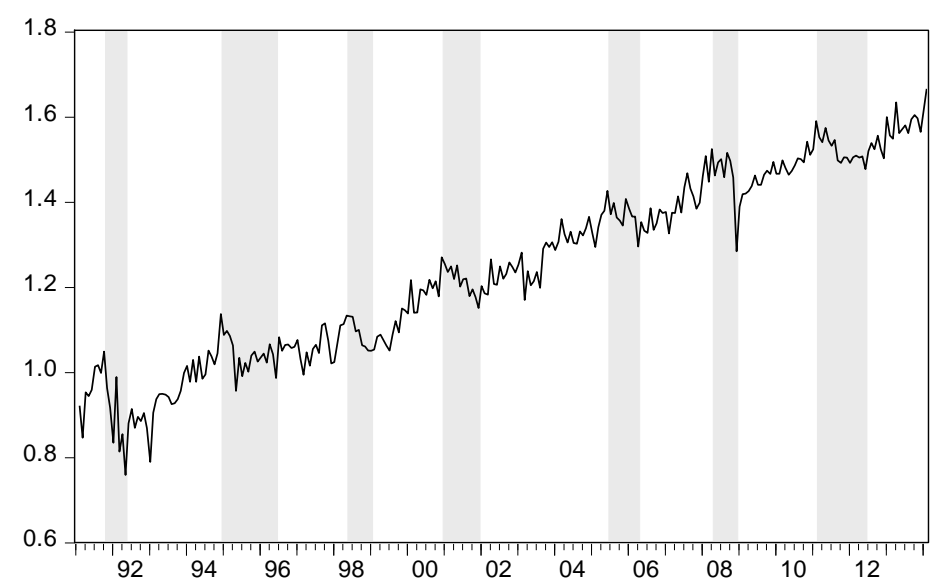

Figura 3. Indicador coincidente para os setores produtivos de 1991-2014

Fonte: Resultados da pesquisa.

Nota: Áreas cinzas representam recessões nos setores produtivos.

A Tabela 7 apresenta as datas de início e fim das recessões, além de outras estatísticas adicionais. $\mathrm{O}$ indicador retratou sete períodos recessivos com duração média de 10 meses. A queda mais longa se estendeu por um ano e meio e a recessão mais curta durou sete meses (entre outubro de 1991 e maio de 1992). Na amostra como um todo, a produção se retraiu em 10\% a.a., em média, durante as recessões. Entre dezembro de 1994 e junho de 1996, datou-se a queda mais longa no setor. Enquanto isso, entre outubro de 1991 e maio de 1992, verificou-se a maior queda na produção, de aproximadamente $16 \%$, período em que a economia brasileira ainda sofria com a hiperinflação e com os efeitos negativos das medidas de política monetária da época - por exemplo, o "confisco" das poupanças, como argumentado por Baer (2002).

Tabela 7. Recessões de acordo com o indicador coincidente para os setores produtivos, no período de 1991-2014

\begin{tabular}{ccccc}
\hline \multicolumn{5}{c}{ Recessões } \\
\hline Início & Fim & $\begin{array}{c}\text { Duração } \\
\text { (em meses) }\end{array}$ & $\begin{array}{c}\text { Perda (\%) Acumulada } \\
\text { de Pico a Vale }\end{array}$ & $\begin{array}{c}\text { Média } \\
\text { (\%) Anualizada }\end{array}$ \\
\hline Out./91 & Mai./92 & 7 & $-16,14 \%$ & $-27,68 \%$ \\
Dez./94 & Jun./96 & 18 & $-4,75 \%$ & $-3,17 \%$ \\
Mai./98 & Jan./99 & 8 & $-7,10 \%$ & $-10,65 \%$ \\
Dez./00 & Dez./01 & 12 & $-5,34 \%$ & $-5,34 \%$ \\
Jun./05 & Abr./06 & 10 & $-5,16 \%$ & $-6,20 \%$ \\
Abr./08 & Dez./08 & 8 & $-8,90 \%$ & $-13,34 \%$ \\
Fev./11 & Jun./12 & 16 & $-4,44 \%$ & $-3,33 \%$ \\
\hline Média & & 10 & $-7,40 \%$ & $-9,96 \%$ \\
\hline
\end{tabular}

Fonte: Elaboração própria.

A segunda maior queda observada se deu no ano de 2008, mostrando uma boa adaptação do indicador criado à crise que acometeu a economia mundial, que atingiu o Brasil com desvalorizações cambiais, afetando o 
balanço das indústrias cujos investimentos guardavam forte relação com financiamentos internacionais e com a redução dos influxos comerciais.

$\mathrm{Na}$ Tabela 8, apresentam-se as estatísticas referentes às expansões econômicas dos setores de média e alta tecnologia. Suas fases de crescimento duraram mais do que as recessões, em média, perdurando por 26 meses. Todavia, o crescimento percentual observado (anualizado) foi menor do que as quedas, em torno de 7,7\%. Entre junho de 1992 e novembro de 1994, durante a primeira expansão detectada, observou-se um crescimento de $12 \%$ a.a. no indicador, sugerindo uma boa adaptação do setor como um todo às mudanças ocorridas na condução da política econômica durante o período de estabilização, nos primeiros anos da década de 90, resultado aproximado ao encontrado na análise para a indústria geral. Destaca-se, ainda, o maior período em que o setor permaneceu em expansão, correspondente ao intervalo entre janeiro de 2002 e maio de 2005.

Nesse ínterim, após considerável redução nos indicadores de risco-país e incerteza, o país experimentou uma fase propícia à produção industrial, com um quadro externo favorável e uma sustentada depreciação cambial (WERNECK, 2014). Ao longo desses 40 meses, o indicador registrou um crescimento anual de 5,59\% na produção dos setores de média e alta tecnologia.

Tabela 8. Expansões de acordo com o indicador coincidente para os sete setores produtivos, no período de 1991-2014

\begin{tabular}{ccccc}
\hline \multicolumn{5}{c}{ Expansões } \\
\hline Início & Fim & $\begin{array}{c}\text { Duração (em } \\
\text { meses) }\end{array}$ & $\begin{array}{c}\text { Cresc. (\%) Acumulado } \\
\text { de Pico a Vale }\end{array}$ & $\begin{array}{c}\text { Média } \\
\text { (\%) Anualizada }\end{array}$ \\
\hline Jun./92 & Nov./94 & 29 & $29,23 \%$ & $12,10 \%$ \\
Jul./96 & Abr./98 & 21 & $4,71 \%$ & $2,69 \%$ \\
Fev./99 & Nov./00 & 21 & $20,61 \%$ & $11,78 \%$ \\
Jan./02 & Mai./05 & 40 & $18,65 \%$ & $5,59 \%$ \\
Mai./06 & Mar./08 & 22 & $12,71 \%$ & $6,93 \%$ \\
Jan./09 & Jan./11 & 24 & $14,50 \%$ & $7,25 \%$ \\
\hline Média & & 26 & $16,74 \%$ & $7,72 \%$ \\
\hline
\end{tabular}

Fonte: Elaboração própria.

Uma vez que a capacidade de predizer as movimentações cíclicas é um aspecto relevante para o planejamento do setor e para a formulação de políticas, o indicador coincidente foi decomposto em fatores, seguindo a metodologia descrita acima, na seção referente ao modelo econométrico desenvolvido para tanto. Como se pode observar na Figura 4, o método de séries de tempo apresentou ótima aderência aos resultados da datação do modelo clássico (business cycle). A respeito disso, percebe-se que a série cíclica AR(1) (em azul) sobe nas áreas brancas e cai nas regiões acinzentadas do gráfico. Assim, a decomposição tendência-ciclo de Harvey (1993), entre outros, pode ser um bom guia para a previsão dos ciclos nos setores considerados. Ademais, a série cíclica obtida permite averiguar outros 
padrões de comportamento da produção de média e alta tecnologia ao longo do tempo.

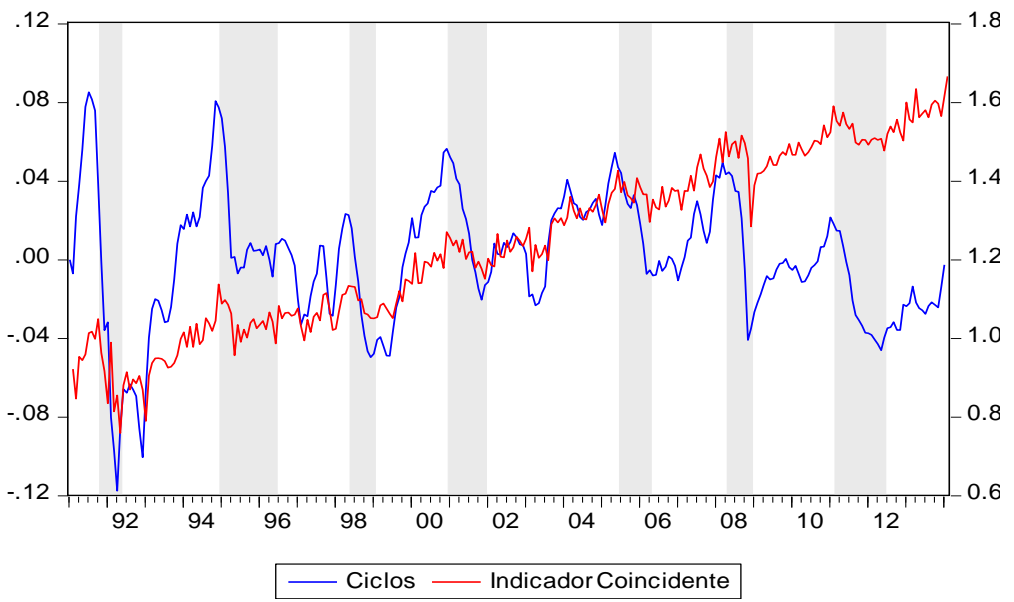

Figura 4. Resultados da decomposição tendência-ciclo para os setores produtivos no período de 1991-2014

Fonte: Resultados da pesquisa.

Notas: Áreas cinzas representam recessões de acordo com o método clássico de datação. A série cíclica é marcada no eixo esquerdo da figura e o indicador coincidente, no direito.

Nesse sentido, a Figura 5 reflete a volatilidade (parte a) e a autocorrelação (parte b) da série cíclica obtida. Na primeira parte, apresenta-se o erro padrão móvel da série do indicador coincidente, com seis observações defasadas. O resultado mostra que há uma tendência de redução no nível da volatilidade do indicador da produção ao longo do tempo, principalmente após a estabilização da inflação na economia, em meados de 1994. Além disso, observa-se que a volatilidade tende a crescer previamente às recessões, atingindo picos quando estas se consolidam (demarcadas, na Figura, pelas áreas acinzentadas).

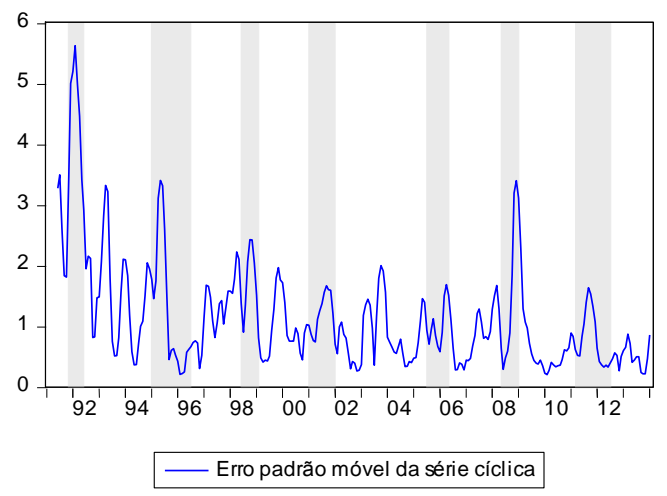

(a)

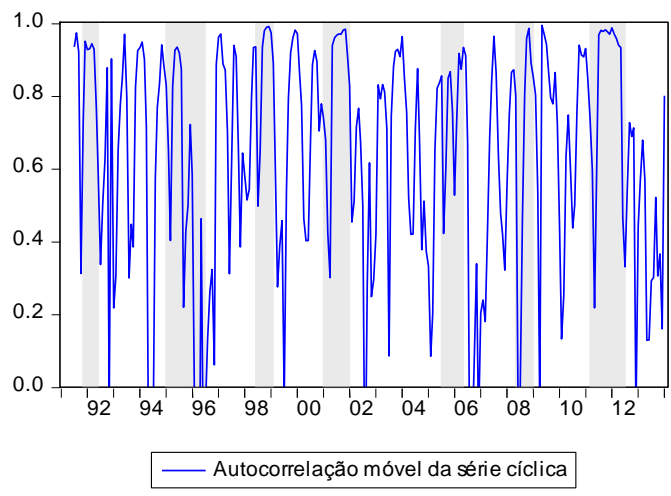

(b)

Figura 5. Volatilidade e autocorrelação na série cíclica do indicador coincidente

Fonte: Resultados da pesquisa. 
Quanto à autocorrelação da série cíclica, também tomada a partir das seis observações antecedentes, verifica-se um padrão oscilante, com média próxima a 0,7. Logo, modela-se bem a autocorrelação como relativamente alta no período, o que indica que um choque no setor produtivo intensivo em tecnologia apresenta intervalo longo de dissipação, isto é, frente a choques positivos ou negativos, a produção do setor somente retornará à sua tendência após vários meses.

\section{CONSIDERAÇÕES FINAIS}

Este trabalho analisou o comportamento cíclico de sete setores intensivos em tecnologia no Brasil, durante o período de janeiro de 1991 a fevereiro de 2014 , bem como a co-movimentação entre os diferentes setores e a atividade econômica agregada, medida aqui pelo índice da produção industrial geral. Os ciclos econômicos identificados para a atividade industrial geral revelam durações diversas, oscilando entre nove meses e, aproximadamente, cinco anos. Quanto às fases em específico, pode-se diferenciá-las da seguinte forma: períodos de expansão, com duração média de 2,2 anos e taxa de crescimento de $2 \%$ a.a.; e períodos recessivos, com duração média de 1,4 anos e perdas anualizadas de 1,4\%.

Os setores também apresentaram dinâmicas diversas quanto à duração e amplitude das fases dos ciclos, sendo alguns deles consideravelmente discrepantes com relação aos valores encontrados para a indústria geral. A duração das expansões variou entre 1,1 e 3,4 anos, sendo a primeira observada no setor de equipamentos elétricos e de comunicação, e a segunda, no setor de construção e montagem de aviões. O primeiro segmento também se destaca quanto à amplitude do crescimento associado à fase expansiva, em que a taxa de crescimento foi de aproximadamente $10 \%$ a.a. Em contraposto, a menor taxa observada foi referente à produção de petróleo, de cerca de 1,45\% a.a. nas expansões. Não obstante, o setor de construção e montagem de aviões foi o que apresentou maior perda média acumulada nas recessões, de $13 \%$ a.a. As fases recessivas foram mais curtas para todos os sete setores, variando de 11 meses a 1,5 anos de duração.

A comparação dos resultados encontrados para a indústria geral com os extraídos dos setores individuais revela uma maior sensibilidade dos setores, uma vez que as flutuações a eles relacionadas, ainda que mais curtas, se mostraram mais acentuadas do que as da série referente à atividade agregada. Tal resultado ilustra o fato de que os setores de média e alta tecnologia são mais voláteis (instáveis) do que a indústria como um todo.

As análises das matrizes de correlação das fases, bem como do índice de difusão, embasaram a criação do indicador coincidente para a atividade produtiva nos ramos intensivos em tecnologia. $\mathrm{O}$ comparativo com a atividade industrial agregada leva à noção de que há elevado grau de comovimentação entre os ciclos da produção industrial setorial e geral. Isto é, os setores de tecnologia respondem aos choques ou políticas expansivas e recessivas quase ao mesmo tempo que a indústria como um todo. Em 
termos de impacto da condução de políticas de cunho industrial, tal levantamento é de grande valia, uma vez que, conhecendo as possíveis respostas do setor às oscilações, medidas específicas podem vir a ser tomadas. Por exemplo, como há grande co-movimentação entre setores tecnológicos e atividade agregada, sinalizações de que a economia irá iniciar uma recessão (ou expansão) indicam que os setores analisados pela respectiva pesquisa também começarão tal movimento cíclico, porém, com flutuações mais acentuadas.

Por fim, afirma-se que o método de decomposição tendência-ciclo é um bom meio de caracterizar (e prever) flutuações nesse ramo de atividade produtiva. A partir dele, pôde-se inferir que os setores analisados se tornaram menos voláteis nos últimos anos, mas, em comparação com o agregado da produção industrial, suas oscilações ainda são destacadas. Ademais, o setor se mostrou bastante sensível a choques na economia, passando por um longo período até a dissipação dos seus efeitos sobre a produção.

Se é de interesse dos gestores implementar políticas de cunho industrial, a escolha dos setores alvos é de suma importância, principalmente em um ambiente de preocupação crescente com a gestão responsável das finanças públicas. O presente estudo recomenda que os ramos produtivos de média e alta tecnologia sejam destinatários plausíveis dos recursos, em função de suas oscilações mais acentuadas que a média, de sua boa co-movimentação com a atividade agregada (o que facilita previsões de turning points) e de sua relevância para o desempenho em longo prazo.

\section{AGRADECIMENTOS}

Os autores agradecem à Fundação de Amparo à Pesquisa do Estado de Minas Gerais (FAPEMIG) pelo apoio e suporte financeiro fornecidos (processo número CSA-APQ-02068-16).

\section{REFERÊNCIAS}

ABREU, M. P.; WERNECK, R. L. F. Estabilização, abertura e privatização. 1990-1994. In: ABREU, M. P. A ordem do Progresso: Dois Séculos de Política Econômica no Brasil. Rio de Janeiro: Elsevier Brasil, 2014. Cap. 15, p. 313330.

BAER, W. Economia brasileira. São Paulo: Nobel, 2002.

BRY, G.; BOSCHAN, C. Programmed selection of cyclical turning points. In: Cyclical Analysis of Time Series: Selected Procedures and Computer Programs. New York: National Bureau of Economic Research, NBER, 1971, p. 7-63.

BURNS, A.; MITCHELL, W. C. Measuring Business Cycles. Cambridge, Mass.: National Bureau of Economic Research, NBER, 1946. 590 p. 
CABALLERO, R. J. Macroeconomics after the crisis: time to deal with the pretense-of-knowledge syndrome. National Bureau of Economic Research, NBER Working Paper n. 16429, 2010. 23 p.

CHANG, Y.; HWANG, S. Asymmetric phase shifts in the U.S. industrial production cycles. Review of Economics and Statistics, v. 97, n. 1, p. 116-133, 2015.

CHAUVET, M. The Brazilian business and growth cycles. Revista Brasileira de Economia, v. 56, n. 1, p. 75-106, 2002.

CLARK, P. K. The cyclical component of U.S. economic activity. Quarterly Journal of Economics, v. 102, n. 4, p. 797-814, 1987.

COMITE DE DATAÇÃO DOS CICLOS ECONÔMICOS, CODACE. Comunicado CODACE. Rio de Janeiro: FGV/IBRE, 2015. Disponivel em: <http://portalibre.fgv.br/> Acesso em: 11 janeiro 2018.

DUARTE, A. J.; ISSLER, J. V.; SPACOV, A. Indicadores coincidentes de atividade econômica e uma cronologia de recessões para o Brasil. Pesquisa e Planejamento Econômico, v. 34, n. 1, p. 1-38, 2004.

EVANS, M.; WACHTEL, P. Inflation regimes and the sources of inflation uncertainty. Journal of Money, Credit and Banking, v. 25, n. 3, p. 475-511, 1993.

FISCHER, S. The role of macroeconomic factors in growth. Journal of Monetary Economics, v. 32, n. 3, p. 485-512, 1993.

FREITAS, M. C. P. Os efeitos da crise global no Brasil: aversão ao risco e preferência pela liquidez no mercado de crédito. Estudos Avançados, v. 23, n. 66, p. 125-145, 2009.

FRIEDMAN, M. Nobel Lecture: Inflation and Unemployment. Journal of Political Economy, v. 85, n. 3, p. 451-472, 1977.

HARDING, D.; PAGAN, A. Dissecting the cycle: a methodological investigation. Journal of monetary economics, v. 49, n. 2, p. 365-381, 2002.

HARDING, D.; PAGAN, A. Synchronization of cycles. Journal of Econometrics, v. 132, n. 1, p. 59-79, 2006.

HARVEY, A. C.; JAEGER, A. Detrending, stylized facts and the business cycle. Journal of applied econometrics, v. 8, n. 3, p. 231-247, 1993.

HOLLAUER, G.; ISSLER, J. V.; NOTINI, H. H. Novo indicador coincidente para a atividade industrial brasileira. Economia Aplicada, v. 13, n. 1, p. 5-28, 2009.

KING, R. et al. Stochastic trends and economic fluctuations. American Economic Review, v. 81, n. 4, p. 819-840, 1991. 
KYDLAND, F.; PRESCOTT, E. Time to Build and Aggregate Fluctuations. Econometrica, v. 50, n. 6, p. 1345-1370, 1982.

LONG, J. B.; PLOSSER, C. I. Sectoral vs. aggregate shocks in the business cycle. American Economic Review, v. 77, n. 2, p. 333-336, 1987.

LOPES, L. S.; MACEDO, L. R.; TOYOSHIMA, S. H. Integração fracionária nos ciclos econômicos de longo prazo no Brasil: Evidências iniciais de criticalidade auto-organizada. Revista Brasileira de Economia, v. 70, n. 4, p. 315-335, 2016.

MORLEY, J. C.; NELSON, C. R.; ZIVOT, E. Why are the Beveridge-Nelson and unobserved-components decompositions of GDP so different? Review of Economics and Statistics, v. 85, n. 2, p. 235-243, 2003.

NASSIF, A. Há evidências de desindustrialização no Brasil? Brazilian Journal of Political Economy, v. 28, n. 1, p. 72-96, 2008.

NELSON, C.; PLOSSER, C. Trends and random walks in macroeconomic time series: Some evidence and implications. Journal of Monetary Economics, v. 10, n. 2, p. 139-162, 1982.

PASTORE, A. C.; GAZZANO, M.; PINOTTI, M. C. Por que a produção industrial não cresce desde 2010? In: BACHA, E.; BOLLE, M. B. (Orgs.). O futuro da indústria no Brasil: desindustrialização em debate. Rio de Janeiro: Civilização Brasileira, 2013.

PERRON, P.; WADA, T. Let's take a break: Trends and cycles in US real GDP. Journal of monetary Economics, v. 56, n. 6, p. 749-765, 2009.

PLOSSER, C. Understanding Real Business Cycles. Journal of Economic Perspectives, v. 3, n. 3, p. 51-77, 1989.

SHEA, J. Complementarities and comovements. Journal of Money, Credit, and Banking, v. 34, n. 2, p. 412-433, 2002.

SLUTZKY, E. The summation of random causes as the source of cyclic processes. Econometrica, v. 5, n. 2, p. 105-146, 1937.

SOLOW, R. M. A contribution to the theory of economic growth. Quarterly Journal of Economics, v. 70, n. 1, p. 65-94, 1956.

UNITED NATIONS CONFERENCE ON TRADE AND DEVELOPMENT, UNCTAD. Trade and Development Report. New York and Geneva: United Nations, 2002.

WERNECK, R. L. F. Alternância política, redistribuição e crescimento, 20032010. In: ABREU, M. P. A ordem do Progresso: Dois Séculos de Política Econômica no Brasil. Rio de Janeiro: Elsevier Brasil, 2014. Cap. 17, p. 357381. 
ZARNOWITZ, V.; OZYILDIRIM, A. Time series decomposition and measurement of business cycles, trends and growth cycles. Journal of Monetary Economics, v. 53, n. 7, p. 1717-1739, 2006.

\section{ANEXO}

Tabela 1A. Correlação par a par entre as fases de queda

\begin{tabular}{l|ccccccc|} 
& S1 & S2 & S3 & S4 & S5 & S6 & S7 \\
S1 & $\mathbf{1 0 0}$ & 51,80 & 55,76 & 58,63 & 44,24 & 45,32 & 44,96 \\
S2 & 51,80 & $\mathbf{1 0 0}$ & 70,86 & 70,86 & 51,44 & 61,15 & 46,40 \\
S3 & 55,76 & 70,86 & $\mathbf{1 0 0}$ & 57,55 & 48,20 & 43,53 & 54,68 \\
S4 & 58,63 & 70,86 & 57,55 & $\mathbf{1 0 0}$ & 63,31 & 60,07 & 56,83 \\
S5 & 44,24 & 51,44 & 48,20 & 63,31 & $\mathbf{1 0 0}$ & 55,76 & 57,55 \\
S6 & 45,32 & 61,15 & 43,53 & 60,07 & 55,76 & $\mathbf{1 0 0}$ & 52,88 \\
S7 & 44,96 & 46,40 & 54,68 & 56,83 & 57,55 & 52,88 & $\mathbf{1 0 0}$
\end{tabular}

Fonte: Resultados da pesquisa.

Nota: S1 a S7 se referem, respectivamente, aos ramos de construção e montagem de aviões; equipamentos elétricos e de comunicação; produção de petróleo; produtos farmacêuticos; produtos plásticos; produtos químicos; e veículos automotores.

Tabela 2A. Correlação par a par entre as fases de crescimento

\begin{tabular}{l|ccccccc|} 
& S1 & S2 & S3 & S4 & S5 & S6 & S7 \\
S1 & $\mathbf{1 0 0}$ & 52,16 & 57,91 & 60,43 & 46,40 & 46,40 & 48,92 \\
S2 & 52,16 & $\mathbf{1 0 0}$ & 70,50 & 72,30 & 56,83 & 64,03 & 50,00 \\
S3 & 57,91 & 70,50 & $\mathbf{1 0 0}$ & 58,63 & 53,24 & 44,60 & 55,76 \\
S4 & 60,43 & 72,30 & 58,63 & $\mathbf{1 0 0}$ & 68,71 & 64,39 & 61,87 \\
S5 & 46,40 & 56,83 & 53,24 & 68,71 & $\mathbf{1 0 0}$ & 61,15 & 60,79 \\
S6 & 46,40 & 64,03 & 44,60 & 64,39 & 61,15 & $\mathbf{1 0 0}$ & 56,47 \\
S7 & 48,92 & 50,00 & 55,76 & 61,87 & 60,79 & 56,47 & $\mathbf{1 0 0}$
\end{tabular}

Fonte: Resultados da pesquisa.

Nota: S1 a S7 se referem, respectivamente, aos ramos de construção e montagem de aviões; equipamentos elétricos e de comunicação; produção de petróleo; produtos farmacêuticos; produtos plásticos; produtos químicos; e veículos automotores. 